\title{
Güneydoğu Anadolu Bölgesi Jüvenil İdiyopatik Artrit Hastalarında Alt Tip Dağılımı ve Üveit Sıklığı
}

\author{
Subtype Distribution and Frequency of Uveitis in Southeastern Anatolian Children with \\ Juvenile Idiopathic Arthritis
}

\section{Mustafa ÇAKAN ${ }^{1}$, Kübra ÖZTÜRK ${ }^{2}$}

1. Şanlıurfa Eğitim ve Araștırma Hastanesi, Çocuk Romatoloji Kliniği, Şanlıurfa ,Türkiye

2. Gaziantep Cengiz Gökçek Kadın Doğum ve Çocuk Hastalıkları Hastanesi, Çocuk Romatoloji Kliniği, Gaziantep, Türkiye

\section{$\ddot{O Z E T}$}

Amaç: Juvenil idiyopatik artrit (JIA) tüm dünyada en s1k gözlenen çocukluk çağı romatizmal hastalığıdır. Tek bir hastalık olmayıp alt gruplardan oluşmaktadır. Kas iskelet sistemi dışında üveit şeklinde göz tutulumu önemli bir morbidite nedenidir. Çalışmamızın amacı kliniklerimizde takip edilen JIA hastaların alt tip dağılımını ve üveit sıklığını saptamaktır.

Gereçler ve Yöntem: Kliniklerimizde JIA tanısı ile takip ve tedavi edilen tüm hastaların dosyaları geriye dönük olarak taranmıştır.

Bulgular: Çalışmamıza 264 JİA hastası dahil edilmiştir. Hastaların \%54.9'u kız iken \%45.1'i erkek idi ve ortalama takip süresi $13.8 \pm 5.8$ ay idi. JïA alt tip dağılımına bakıldığında en sık oligoartiküler JIA (\%42.4) gözlenmekte idi. Entezit ilişkili artrit (\%21.6) ikinci sırada iken diğer JİA alt tip dağılımı şu şekilde idi; sistemik JIA (\%13.6), romatoid faktör (RF) negatif poliartiküler JİA (\%10.2), RF pozitif poliartiküler Jİ (\%9.5), psoriatik artrit $(\% 1.9)$ ve siniflandirılamayan artrit $(\% 0.8)$ Üveit toplam 23 hastada (\%8.7) gözlenmiş olup üveit hastalarının \%91.3'ü oligoartiküler JIAA grubunda idi. Sistemik JİA hastalarının \%13.8' inde makrofaj aktivasyon sendromu gözlendi. Son kontroldeki hastalık aktivitesine bakıldığında hastaların \%18.6's1 aktif iken \%81.4'ü remisyonda takip edilmekteydi.

Sonuç: Ülkemizde en sık gözlenen JİA alt tipi diğer ülkelerde olduğu gibi oligoartiküler JíA'dır. Ancak batı ülkelerinden farklı olarak ikinci en sık gözlenen alt tip entezit ilişkili artrittir. Ülkemiz JïA hastalarının diğer bir farkı da, JİA ilișkili üveitin daha az gözlenmesidir. Oligoartiküler JİA üveitin en sık gözlendiği alt gruptur. Güncel tedavi seçeneklerinin artması ile hastaların büyük çoğunluğunda hastalık remisyonu sağlanabilmektedir.

Anahtar Kelimeler: juvenile idiopatik artrit, üveit, çocuk

\begin{abstract}
Objective: Juvenile idiopathic arthritis (JIA) is the most common rheumatic disease of childhood in the world. It is not a single disease rather composed of distinct subtypes. Apart from musculoskeletal complications, uveitis is one of the major causes of morbidity in JIA. The aim of this study was to demonstrate subtype distribution and frequency of uveitis in JIA.
\end{abstract}

Material and Methods: The study was conducted in two pediatric rheumatology centers of Southeastern part of Turkey.

\section{İletişim}

Sorumlu Yazar: Mustafa ÇAKAN

Adres: Yenice Mh., Yenice Yolu No: 1, Şanlıurfa Eğitim ve Araştırma Hast., Çocuk Romatoloji Kliniği 63250 Eyyübiye, Şanlıurfa, Türkiye Tel: +90 (505) 3946344

E-Posta: mustafacakan@hotmail.com

Makale Geliș: 11.07.2019

Makale Kabul: 07.02.2020

DOI: http://dx.doi.org/10.16948/zktipb.590889
Results: The cohort consisted of 264 children with slightly female predominance (females: $54.9 \%$, males: $45.1 \%$ ). Mean duration of follow-up was $13.8 \pm 5.8$ months. The most common subtype was oligoarticular JIA (42.4\%) followed by enthesitis related arthritis $(21.6 \%)$. The distribution of other subtypes were as follows; systemic JIA (13.6\%), rheumatoid factor (RF) negative polyarticular JIA (10.2\%), RF positive polyarticular JIA $(9.5 \%)$, psoriatic arthritis $(1.9 \%)$ and unclassified arthritis $(0.8 \%)$. The frequency of uveitis was $8.7 \%$ and $91.3 \%$ of the patients with uveitis had oligoarticular JIA. Macrophage activation syndrome was observed in $13.8 \%$ of systemic JIA patients. While $18.6 \%$ of the patients had active disease at the time of enrollment, $81.4 \%$ had remission.

Conclusion: As in other parts of the world, oligoarticular JIA is the most common subtype in our country. But, in contrast to western countries, enthesitis related arthritis is the second most common subtype in Turkey. The frequency of uveitis is low in Turkish JIA children that is another major difference from the western countries and oligoarticular JIA is the most common subtype associated with uveitis. With the introduction of newer treatment modalities, remission is an achievable goal in most of the JIA patients.

Keywords: juvenile idiopathic arthritis, uveitis, child

\section{GİRIŞ}

Juvenil idiyopatik artrit (JİA) tüm dünyada en sık gözlenen çocukluk çağı romatizmal hastalığ1dır $(1,2)$. Ülkemizde Ailevi Akdeniz Ateşi en s1k gözlenen romatizmal hastalık olup JíA ikinci sırada yer almaktadır. JiA tek başına bir hastalık olmayıp 6 haftayı geçen ve başka bir nedenle açıklanamayan artriti olan çocuk hastaları kapsayan genel bir tanımdir. ILAR (International League of the Association for Rheumatology) sinıflamasina göre JIA oligoartiküler JİA (persistan veya uzamış), sistemik JIA, romatoid faktör (RF) negatif poliartiküler JïA, RF pozitif poliartiküler JIA, entezit ilișkili artrit (EİA), psoriatik artrit ve sinıflandirılamayan artrit olmak üzere 7 gruba ayrılmaktadır. Her grubun ayrı tanımlayıcı ve dışlayıcı kriterleri bulunmaktadır. ILAR kriterleri ilk olarak 1997 y1lında yayınlanmış ve 2001 yilında revize edilmiştir (3). ILAR sinıflamasının değişmesi gerektiği ve yeni sınıflama önerileri yayınlanmış olsa da ILAR sınıflama kriterleri ve tanımları halen güncelliğini korumaktadır (4).

Oligoartiküler JİA tüm dünyada en sık gözlenen JíA alt tipini oluşturmaktadır. Batı ülkelerinde ikinci en sık gözlenen grup RF negatif poliartiküler JİA'dır $(1,5)$. Ülkemizde yapılan alt tip analiz çalışmalarında oligoartiküler JíA yine en sik alt tip olarak bulunmuştur. Ancak ülkemizde ve diğer 
Asya ülkelerinde olduğu gibi EİA batı ülkerine göre belirgin olarak daha sık gözlenmektedir (6-9).

Gözün vasküler yapılar açısından zengin orta tabakasına üvea denilmektedir. Üveit üvea tabakasının inflamasyonuna denilir ve çocuklarda üveite neden olan en sık sistemik hastalık JíA'dır. Üveit akut veya kronik ön üveit (iridosiklit) şeklinde olabilir. Akut ön üveit en sık EİA'da gözlenip çoğunlukla hızla düzelmekle birlikte oligoartiküler JİA'da daha sık gözlenen kronik ön üveit erken tanınıp tedavi edilmediği takdirde körlüğe kadar ilerleyebilen progresif bir seyir gösterir. Kız cinsiyet, oligoartiküler alt tip, küçük yaş ve antinükleer antikor (ANA) pozitif olması kronik ön üveit için ana risk faktörlerini oluşturmaktadır (10-11).

Calıșmamızın amacı kliniklerimizde JİA tanısı ile takip edilen hastaların alt tip dağılımını, remisyon oranlarını ve üveit sıklığını saptamaktır.

\section{GEREÇ ve YÖNTEM}

Çalışmaya Gaziantep ve Şanlıurfa illerindeki çocuk romatoloji polkliniklerinde Temmuz 2017 ile Temmuz 2019 yılları arasinda JiA tanısı ile takip ve tedavi edilen hastalar alınmıştır. Hastaların dosyaları geriye dönük olarak taranarak JiA alt tipi, cinsiyet, yaş, üveit varlığı, takip süresi, kullanılan ilaçlar ve son kontrolde hastalık durumu bilgileri alınmıştır. Çalışmaya dahil olmak için hastanın JíA tanısının olmas1, düzenli kontrollere geliyor olmas1, ilk tan1 anından sonra en az 6 ay geçmiş olması kriterleri aranmıştır. JİA sınıflaması ILAR kriterlerine göre (3), üveit tanımı SUN (Standardization of Uveitis Nomenclature) kriterlerine göre yapılmıştır (11). Hastalık aktivitesini değerlendirmek için 2011 y1lında Wallace ve ark. tarafından yayımlanan klinik inkatif hastalık tanımlama kriterleri kullanılmıştır (12). ANA çalışması indirekt immünofloresan yöntemle yapılmış olup $\geq 1: 100$ titreler pozitif olarak kabul edilmiştir. Çalışmaya katılan tüm hastalardan aydınlatılmış onam alınmıştır. Klinik ve demografik özellikler devamlı değişkenler için ortalama ve standart sapma, kategorik değişkenler içinde yüzde ve sayı olarak verilmiştir. İstatiksel analizler SPSS (version 22.0; SPSS, Chicago, IL, USA) ile yapilmiştır.

\section{BULGULAR}

Çalışmaya 264 hasta dahil edilmiştir. Ortalama tanı yaşı $9.3 \pm 4.8$ yıl iken, ortalama takip süresi $13.8 \pm 5.8$ ay idi. Hastaları JİA alt tip ve cinsiyet dağılımı Tablo 1'de verilmiştir.

Tablo 1: JïA alt tip ve cinsiyet dağılımı. JİA: jüvenil idiyopatik artrit, RF: romatoid faktor.

\begin{tabular}{|l|l|l|}
\hline JİA alt tipi & Sıklık (n/\%) & Cinsiyet (kız/erkek) \\
\hline Oligoartiküler J̇̇ & $112(\% 42.4)$ & $73 / 39$ \\
\hline Entezit ilişkili artrit & $57(\% 21.6)$ & $14 / 43$ \\
\hline Sistemik Ji̇A & $36(\% 13.6)$ & $19 / 17$ \\
\hline RF negatif poliartiküler J̇A & $27(\% 10.2)$ & $17 / 10$ \\
\hline RF pozitif poliartiküler JİA & $25(\% 9.5)$ & $20 / 5$ \\
\hline Psoriatik artrit & $5(\% 1.9)$ & $1 / 4$ \\
\hline Sinıflandırılamayan artrit & $2(\% 0.8)$ & $1 / 1$ \\
\hline Toplam & $264(\% 100)$ & $145 / 119$ \\
\hline
\end{tabular}

Çalışmamızda en sık saptanan JİA alt tipi $\% 42.4$ ile oligoartiküler JİA olmuştur. Oligoartiküler JİA'ların dağılımına bakıldığında hastaların \%91'inin (102 hasta) persistan oligoartiküler JİA olduğu ve uzamıș oligoartiküler JíA'nın sadece \%9'unda (10 hasta) gözlendiği görülmüştür. İkinci en sik saptanan alt grup olarak \%21.6 ile EİA yer almaktadır. En az görülen alt tip ise \%0.8 ile sinıflandırılamayan artrit olmuştur.

Cinsiyet dağılımına bakıldığında hastaların \%54.9'u kiz iken, \%45.1'i erkek idi. EİA ve psoriatik artritte erkek hakimiyeti mevcut iken diğer tüm alt gruplarda kız hakimiyeti mevcut idi. Sinıflandırılamayan artrit grubundaki iki hastadan biri persistan oligoartiküler JİA diğeri ise RF negatif poliartiküler JIA grubunda yer almakta idi ancak her iki hastanında birinci derece akrabalarında sedef hikayesi mevcut olduğu için sınıflandırılamayan artrit grubuna dahil edilmiştir.

Üveit s1klığ1 tüm kohortta \%8.7 (23 hasta) olarak bulunmuştur. Üveit hastalarının \%91.3'ünü (21 hasta) oligoartiküler JİA hastaları oluştururken sadece 2 EİA hastasında üveit gözlenmiştir. Diğer alt gruplarda ise üveit saptanmamıştır. Üveit hastalarının \%69.5'i kız iken hastaların \%43.4'ünde ANA pozitif idi. Tüm JİA hastalarında ANA pozitiflik oran $1 \% 24.6$ iken, en s1k ANA pozitif saptanan grup \%61.7 ile oligoartiküler JíA olmuştur. İki EİA hastasında üveit akut ön üveit şeklinde iken diğer tüm oligoartiküler JİA hastalarında kronik asemptomatik ön üveit şeklinde idi.

Kohorttaki 36 sistemik JİA hastasının 5'inde (\%13.8) makrofaj aktivasyon sendromu (MAS) gözlenmiştir. Sistemik JíA'ların ilk tanı sonrası klinik seyirlerine bakıldığında monosiklik gidişat \%44.4'ünde, polisiklik gidişat \%16.6'sında, persis$\tan$ (kronik poliartiküler) seyir \%41.6'sında gözlenmiştir.

Son kontrolde hastalık aktivitesine bakıldığında hastaların \%81.4'ü remisyonda iken \%18.6's1 aktif idi. JİA alt tiplerine göre remisyon oranları Tablo 2 de verilmiştir. En fazla aktif hasta içeren gruplar psoriatik artrit (\%40.0), RF pozitif poliartiküler JİA (\%32.0) ve RF negatif poliartiküler JİA (\%22.2) iken siniflandırılamayan artrit $(\% 100)$ ve sistemik Jं̇ $(86.2 \%)$ en fazla remisyonun sağlandığ tipleri olmuştur.

Tablo 2: JİA alt tiplerine göre hastaların remisyon oranları. JİA: jüvenil idiyopatik artrit, RF: romatoid faktör.

\begin{tabular}{|l|l|l|}
\hline J̇̇ alt tipi & Aktif (n/\%) & Remisyonda (n/\%) \\
\hline Oligoartiküler JİA & $19(\% 16.9)$ & $93(\% 83.1)$ \\
\hline Entezit ilişkili artrit & $9(\% 15.7)$ & $48(\% 84.3)$ \\
\hline Sistemik JİA & $5(\% 13.8)$ & $31(\% 86.2)$ \\
\hline RF negatif poliartiküler J̇̇ & $6(\% 22.2)$ & $21(\% 77.2)$ \\
\hline RF pozitif poliartiküler JİA & $8(\% 32.8)$ & $17(\% 67.2)$ \\
\hline Psoriatik artrit & $2(\% 40.0)$ & $3(\% 60.0)$ \\
\hline Sinıflandırılamayan artrit & $0(\% 0.0)$ & $2(\% 100)$ \\
\hline Toplam & $49(\% 18.6)$ & $215(\% 81.4)$ \\
\hline
\end{tabular}




\section{TARTIȘMA}

Güneydoğu Anadolu Bölgesi JİA hastalarında en sık gözlenen alt tip, ülke genelinde olduğu gibi oligoartiküler JİA'dır. İkinci en sık gözlenen alt tip EİA'dır. Üveit hastaların az bir kısmında gözlenirken, oligoartiküler JİA ve kız cinsiyet üveit gelişimi için en önemli risk faktörleri olarak bulunmuştur. Psoriatik artrit hastaları ve poliartiküler tutulumu olan hastalar remisyon oranının en az sağlandığı gruplar olmuştur.

Jüvenil idiyopatik artrit çocukluk çağında tüm dünyada en s1k gözlenen romatolojik hastaliktır. ILAR sinıflamasına göre JİA 7 alt gruba ayrilmaktadır. JİA alt grupları dağılımı ülkeden ülkeye farkl1l1k göstermektedir. Bazı alt tipler farklı coğrafyalarda daha s1k gözlenmektedir. Oligoartiküler JİA tüm dünyada en s1k gözlenen alt grubu olușturmaktadır. Batı ülkeleri verilene göre tüm JİA'ların \%56.7'sini oligoartiküler JİA oluşturmaktadır (5). Ülkemiz de yapılan çok merkezli bir çalışmada oligoartiküler JiA siklığ $1 \% 41.0$ olarak bulunmuștur (6). Yine başka bir çalıșmada oligoartiküler JïA \%32.9 ile Türk JİA çocuklarında da en sık saptanan alt grup olmuştur (9). Batı ülkelerinde RF negatif poliartiküler JïA \%31.5 ile en s1k ikinci alt grup iken ülkemizde (\%32.9) ve diğer Asya ülkelerinde (\%29.8) EİA ikinci sırada yer almaktadır $(5,9)$. Bu farklılık nedeni olarak genetik farklılık, çevre ve mikrobiota etkisi üzerinde durulmaktadır. Bizim çalıșmamızda da oligoartiküler JİA \%42.4 ile en sık saptanan alt tip iken EİA \%21.6 ile ikinci sırada yer almıştır.

Sistemik JİA ateş, döküntü ve serözit ile karakterize bir hastalıktır ve daha çok otoinflamatuar bir tablo görünümünde olduğu için diğer JİA alt gruplarından farklı bir yerde durmaktadır. Ayrıca çocuk romatolojinin en acil durumlarından biri olan ve mortalite ile sonuçlanabilen MAS'a en sik neden hastalık olduğu için ayrı bir öneme sahiptir $(13,14)$. MAS sistemik JIA hastalarının \%15-25'inde gözlenmektedir (13). Ülkemizde 92 sistemik JiA hastasının alındığ 1 bir çalıșmada MAS sıklığ $\% 15.2$ olarak bulunmuştur (6). Çalışmamızda da MAS sıklığ literatür ile uyumlu olarak \%13.8 olarak bulunmuştur. Ayrıca sistemik JiA hastaları takiplerinde monosiklik (tek atak), polisiklik (tekrarlayan ateş ve sistemik bulgularla karakterize ataklar) ve kronik poliartiküler (sistemik bulguların belirgin olmadığ ağırlıklı olarak eklem tutulumunun ön planda olduğu tip) olmak üzere 3 farklı seyir gösterebilir. Monosiklik şeklinde seyreden sistemik JïA hastaları en iyi prognoza sahip iken, tekrarlayan MAS atakları ile seyredebilen polisiklik gidişat ve ağır eklem tutulumları ile seyredebilen kronik poliartiküler seyirli sistemik JIAA hastaları tedavi ve prognoz açısından daha zorlu bir gidişat izlemektedir. Kırk beş sistemik JiA hastasını ortalama 5 y1l takip eden bir çalışmada monosiklik gidişat hastaların \%42.2'sinde, polisiklik gidişat $\% 6.7$ 'sinde, kronik poliartiküler gidişat ise hastaların \%51.1'inde gözlenmiştir. Bizim çalıșmamızda da monosiklik gidişat hastaların yarıya yakınında gözlenirken, kalan çoğunda kronik poliartiküler gidişat gözlenmiştir.

Üveit JİA hastalarında en s1k rastlanan kas-iskelet sistemi dıșı bulgulardan biridir. EİA'da akut kendi kendini sınırlayan ve siklıkla sekelsiz bir kaç hafta içinde düzelen üveit gözlenir iken en sik oligoartiküler JíA olmak üzere diğer alt tiplerde genellikle asemptomatik seyreden sadece düzenli göz taramaları ile saptanabilen ve körlüğe kadar ilerleyebilen kronik ön üveit olmaktadır. Kronik ön üveit için en önemli risk faktörlerini oligoartiküler JİA, kız cinsiyet, 6 yaş altında hastalık başlaması ve ANA pozitifliği oluşturmaktadır. Üveit sıklığı da ülkeden ülkeye değişiklik göstermektedir. Literatürdeki en geniş kapsamlı çalışmada 49 ülkeden 9081 JİA hastasının alındığı çalışmada Avrupa ve Kuzey Amerikada üveit sıklığ $\% 19.1$ bulunur iken gelişmekte olan ülkelerde üveit sıklığ $1 \% 5.9$ olarak bulunmuştur. Ülkemizde de üveitin daha az gözlendiğine dair çalıșmalar mevcuttur. Cessitli çalıșmalarda JIA hastalarında üveit sıklığ $\% 2.6-15.7$ arasında bulunmuştur $(6,8,9,16,17)$. Mevcut çalışmalarda üveit sıklığı yanında ANA pozitifliğine bakıldığında, ANA pozitifliğinin gelişmiş ülkelerde \%70-80'lere kadar çıkmasına rağmen ülkemizde ANA pozitifliği tüm JİA hastalarında \%14.2-\%44 olarak bulunmuştur $(6,8-10,16,17)$. Çalıșmamızda da üveit sıklığ́1 \%8.7 olarak bulunmuştur. Üveit hastalarında kız cinsiyet hakimiyeti mevcut iken ANA pozitiflik oranı yine düşük bulunmuştur (tüm JİA'larda \%24.6, üveit olanlarda \%43.4)

Günümüz ilaç çeșitliğinin artmış olması ile JİA'da tam kür halen uzak bir hayal olmasına rağmen uzun süreli remisyon elde edilmesi mümkün gözükmektedir (18). İlk başta da belirtildiği gibi JíA kendi içinde çok farklı davranan alt gruplar içermektedir ve remisyon oranları alt gruplara göre belirgin farklılık göstermektedir. Ravelli ve ark.'nın çalışmasında persistan oligoartrit grubundaki hastalarının en yüksek remisyon oranına sahip olduğu (\%43-73) ve RF pozitif poliartiküler JïA hastalarının en az remisyon oranına (\%0-15) sahip olan gruplar olduğu belirtilmiştir (19). Psoriatik artritte JíA içinde tedavisi zor bir grubu oluşturmaktadır (20). Serimizde genel olarak yüksek bir remisyon oranı $(\% 81.4)$ yakalanmıș olmasına rağmen psoriatik artrit ile RF negatif poliartiküler ve RF pozitif poliartiküler artrit hastaları remisyon oranının en az olduğu grupları oluşturmuşlardır.

Sonuç olarak Güneydoğu Anadolu Bölgesi Ji̇A hastalarında oligoartiküler JïA en sik rastlanan alt gruptur. Üveit siklığı belirgin olarak düşük bulunmuştur. Başlangıçta poliartiküler tutulumu olan JïA hastaları ve psoriatik artrit hastalarında remisyon oranı diğer gruplara göre daha düşüktür. Bu hastalarda daha erken dönemde ilaç değişikliği yapılmasının önemi bir kez daha gösterilmiştir.

\section{KAYNAKLAR}

1) Crayne CB, Beukelman T. Juvenile idiopathic arthritis: Oligoarthritis and polyarthritis. Pediatr Clin North Am. 2018;65:657-674.

2) Petty RE, Laxer RM, Lucy R, Wedderburn LR. Juvenile Idiopathic Arthritis. In: Petty RE, Laxer RM, Lindsey CB, Wedderburn LR, editors. Textbook of Pediatric Rheumatology. 7th ed. Philadelphia: Elsevier; 2016. pp 188-204.

3) Petty RE, Southwood TR, Manners P, et al. International 
League of Associations for Rheumatology classification of juvenile idiopathic arthritis: second revision, Edmonton, 2001. J Rheumatol 2004;31:390-392.

4) Martini A, Ravelli A, Avcin T, Beresford MW, Burgos-Vargas R, Cuttica R, et al; Pediatric Rheumatology International Trials Organization (PRINTO). Toward new classsification criteria for juvenile idiopathic arthritis: First steps, Pediatric Rheumatology International Trials Organization international concencus. J Rheumatol 2019;46:190-197.

5) Consolaro A, Giancane G, Alongi A, van Dijkhuizen EHP, Aggarwal A, Al-Mayouf SM, et al; Paediatric Rheumatology International Trials Organisation. Phenotypic variability and disparities in treatment and outcomes of childhood arthritis throughout the world: an observational cohort study. Lancet Child Adolesc Health 2019;3:255-263.

6) Demirkaya E, Ozen S, Bilginer Y, Ayaz NA, Makay BB, Unsal E, et al. The distribution of juvenile idiopathic arthritis in the eastern Mediterranean: results from the registry of the Turkish Paediatric Rheumatology Association. Clin Exp Rheumatol 2011;29:111-116.

7) Comak E, Dogan CS, Akman S, Koyun M, Gokceoğlu AU, Keser I. MEFV gene mutations in Turkish children with juvenile idiopathic arthritis. Eur J Pediatr 2013;172:1061-1067.

8) Otar Yener G, Ekici Tekin Z, Akdağ B, Yüksel S. Jüvenil idiyopatik artrit - Pamukkale Universitesi deneyimi. 4. Çocuk Romatoloji Kongresi, 2018, SS015.

9) Çakan M, Aktay-Ayaz N, Keskindemirci G, Ekinci DY, Karadağ ŞG. Subtype frequencies, demographic features and remission rates in juvenile idiopathic arthritis -265 cases from a Turkish center. Turk J Pediatr 2017;59:548-554.

10) Tugal-Tutkun I, Quartier P, Bodaghi B. Disease of the year: juvenile idiopathic arthritis-associated uveitis--classification and diagnostic approach. Ocul Immunol Inflamm 2014;22:56-63.

11) Jabs DA, Nussenblatt RB, Rosenbaum JT; Standardization of Uveitis Nomenclature (SUN) Working Group. Standardization of uveitis nomenclature for reporting clinical data. Results of the first international workshop. Am J Ophthalmol 2005;140:509-516.

12) Wallace CA, Giannini EH, Huang B, Utert L, Ruperto N; Childhood Arthritis Rheumatology Research Alliance; Pediatric Rheumatology Collaborative Study Group; Pediatric Rheumatology International Trials Organization. American College of Rheumatology provisional criteria for defining clinical inactive disease in select categories of juvenile idiopathic arthritis. Arthritis Care Res (Hoboken) 2011;63:929-936.

13) Ravelli A, Grom AA, Behrens EM, Cron RQ. Macrophage activation syndrome as part of systemic juvenile idiopathic arthritis: diagnosis, genetics, pathophysiology and treatment. Genes Immun 2012;13:289-298.

14) Ayaz NA, Ozen S, Bilginer Y, Ergüven M, Taşkiran E, Y1lmaz E, et al. MEFV mutations in systemic onset juvenile idiopathic arthritis. Rheumatology (Oxford) 2009;48:23-25.

15) Singh-Grewal D, Schneider R, Bayer N, Feldman BM. Predictors of disease course and remission in systemic juvenile idiopathic arthritis: significance of early clinical and laboratory features. Arthritis Rheum. 2000;54:1595-1601.

16) Kasapçopur O, Yologlu N, Ozyazgan Y, Ercan G, Caliskan S, Sever L, et al. Uveitis and anti nuclear antibody positivity in children with juvenile idiopathic arthritis. Indian Pediatr 2004;41:1035-1039.
17) Ozdogan H, Kasapçopur O, Dede H, Arisoy N, Beceren T, Yurdakul S, et al. Juvenile chronic arthritis in a Turkish population. Clin Exp Rheumatol 1991;9:431-435.

18) Ravelli A, Consolaro A, Horneff G, Laxer RM, Lovell DJ, Wulffrat NM, et al. Treating juvenile idiopathic arthritis to target: recommendations of an international task force. Ann Rheum Dis 2018;77:819-828.

19) Ravelli A, Martini A. Remission in juvenile idiopathic arthritis. Clin Exp Rheumatol 2006;24:S105-110.

20) Otar Yener G, Ekici Tekin Z, Yuksel S. Psoriatic fasciitis in a pediatric patient: A case report. World J Clin Cases 2019;7:68-72. 